\title{
The Analysis on the Construction Principles of Scientific Research Incentive Mechanism for Young University Teachers
}

\author{
Aichen Liu \\ Jilin Agricultural University, Changchun 130118, China. \\ 9558805@qq.com
}

\begin{abstract}
Incentive is the inducement which inspires people's motivation to make its progress towards the goals. Young university teachers not only need self-incentive, but also need encouragement from others, especially from the superior departments and the leaders at all levels. Scientific research management departments of colleges and universities should actively develop its incentive functions, establish scientific incentive mechanism for young teachers, combine their management objectives and the effective demand of young teachers, and it will help realizing the rapid development of scientific research in colleges and universities. This article summarized the five principles of scientific research incentive mechanism for young university teachers in order to realize the mission and goals of scientific research management in colleges and universities.
\end{abstract}

Keywords: Colleges and universities; young teachers; scientific research; incentive mechanism.

\section{Introduction}

Incentive is one of the important research topics whether in management psychology and organizational behavior. In organizational behavior, it refers to the motivation of people, cause people's behavior, and internal potential of the play, through their own efforts to complete the process and get the goal. In management science or behavioral science, incentive is the inducement which inspires people's motivation to make its progress towards the goals. As young university teachers in the education teaching research of powerhouse, assisted by running a good incentive mechanism from the external environment, the collective, especially from superior departments and leadership, will raise the enthusiasm of young teachers engaged in teaching, scientific research, education teaching effect will be greatly improved, and the quality of teaching will increase greatly. From a practical sense, the construction of young university teachers' scientific research management incentive mechanism and realizing the steady progress of scientific research in colleges and universities, need the organic combination of colleges and universities management goal and the effective demand of young teachers.

The construction of scientific research incentive mechanism for the young teachers in colleges and universities is the inducement which make the young teachers to participate in scientific research actively, is the process that leading the youth research of teachers' code of conduct and values. Therefore, the construction of young university teachers' scientific research incentive mechanism is not only the important guarantee to realize the scientific research management tasks and objectives in colleges and universities, but also contribute to the growth of young teachers and the realization of self-worth. But it should follow certain principles:

\section{The Principle of the Combination of Material and Spiritual Incentive}

To study from the perspective of incentive theory, the needs of people determine the activity which is the premise among many factors, including two aspects of material and spirit. Demand is the main source of power that can arouse people's subjective initiative needs in any activity; it can directly affect people's consciousness of initiative and enthusiasm. The satisfaction of material factors such as living environment, money and treatment cannot produce direct incentive power, but if material conditions were not satisfied, the negative consequences will also affect people's work efficiency, and the quality of life and study. Among college teachers, young teachers belong to a special part of the crowd, they face huge pressure of work and life, because they need to reduce the 
economic burden through the work after getting a master's or doctoral degree; they need to exploit their talent and prove their ability through work, etc. The construction principles of scientific research incentive mechanism undoubtedly provide a platform for young teachers to actively participate in scientific research work, which not only can encourage young teachers in spirit but also guarantee their material. In addition, paying attention to the realization of self-worth and the self improvement is the common characteristic of young teachers; reasonable use of scientific incentive mechanism can provide appropriate incentives to young teachers which can improve the scientific research in colleges and universities. All departments and all levels of leadership in colleges and universities should seize the positive mentality of young teachers that they are eager to be respected, valued and accepted, to stimulate their enthusiasm and spirits of scientific research, as well as to help young teachers lay a solid foundation of developing scientific research. It can urge them to obtain a higher level of achievement. Especially in poor teaching condition areas, school can compensate teachers by spirit incentive instead of the lack of material conditions. Giving teachers more honor and encouragement can achieve good effect to make them feel be empowering. So during the construction of incentive mechanism research for young university teachers, it's necessary to stick to principles of material and spiritual incentive which supplements for each other. The relationships between material incentive and spirit incentive of the incentive mechanism can be summarized as connecting with each other, the difference between each other, promoting each other. Material incentive has the direct and intuitive affect to people which not only being used to stimulate talent themselves but also can improve the working and living conditions of young university teachers through the success of scientific research achievements. Spiritual incentive refers to the factors such as emotion, faith, awards, achievement to influence people's behavior, including giving the honorary title, promoting technical titles, providing the study opportunity, news publishing propaganda, etc., which not only play the role of the booster to the people's behavior, but also compensate the lack of material.

\section{The Principle of the Combination of Positive and Negative Incentive}

In the reinforcement theory, reinforcement refers to when the people decided to make some kind of behavior, this behavior itself or the result plays a decisive role, and when some beneficial result appeared this behavior will appear again; when some kind of behavior as a result of adverse, this behavior will weaken or fade. Positive reinforcement refers to through the increase of material and spiritual two sides (praise, reward, publicity, etc.) to correct human behavior. Through discipline, weaken and criticism of the negative factors such as reduction to correct the person's behavior called negative reinforcement. Scientific research management in colleges and universities should use the combination of positive reinforcement and negative reinforcement to develop youth scientific incentive mechanism; on one hand, give high material and spiritual rewards to the ones have strong scientific research ability, rich of scientific research achievements, performance outstanding, to encourage these teachers to continue research, achieve high level of research results and dig deeper research capacity; On the other hand, punish those who treat appropriately and scientific research, lack of scientific research achievements, performance is not outstanding, but punishment is not an end, but a kind of incentives; through the combination of positive and negative incentive ways to mobilize young university teachers to participate in scientific research of passion, play to their advantages and subjective initiative, improve the overall level of scientific research of university teachers.

\section{The Principle of the Combination of Short-term and Long-term Incentive}

The rationalization, informationization, economic, scientific of contemporary society and many other factors are gradually penetrated into all aspects of the higher education; in such a big background, to comply with the demand of social development, colleges and universities should provide high-level scientific research task. As an important position training of high-level personnel, colleges and universities have higher scientific research level than enterprises, and they provide 
continuous conveying applicability, strongly professional talents for the enterprise and social. So the most remarkable problem of young university teachers' team construction is how to build college teachers team to achieve the goal of the latest scientific research achievements. The incentive mechanism plays an irreplaceable role and the combination of short-term and long-term incentive is more conducive to achieve the desired goal. The young teachers in colleges and universities focus on the effectiveness of incentive, the affirmation and reward need to be given timely because the delays incentive may reduce the young teachers' scientific research enthusiasm and work efficiency. Colleges and universities must establish the long-term incentive mechanism to encourage the young teachers engaged in scientific research work and guarantee the academic freedom and academic independence. In the career planning of young teachers, it is needed to have a clear emphasis on the young teachers to have a clear development direction in the area of scientific research, and specific measures. The young teachers should make their own research and development consistent with the school's research goal. They can deep into the line of scientific research at colleges and universities, strive for advanced high level research achievements through the combination of long-term and short-term incentive mechanism go. Of course, we should consider the enforceability and irreconcilable in establishing incentive mechanism of long-term and short-term incentive. We should not achieve the short-term and immediate interests of the individual at the expense of long-term incentive target.

\section{The Principle of Differentiated Incentive}

It was pointed out in the paper of Maslow's hierarchy of needs that, people of different levels will show different demand of society and their own behavior motivation, the motivated requirements and special requirements also have the advantages of focus, so effective measures should be taken to meet the different needs of different levels of people. Differentiated incentive principles mainly include: (1) the incentives should have targeted, generally the managers make a lot of incentive policy, but the managers can hardly to act according to their hopes, needs or expectations in the process of implementation, because it is not according to the demand by managers to develop targeted incentives; (2) to establish incentive mechanism, we should pay attention to the characteristics of the motivated staff, under normal circumstances, the incentives are flexible use along with different people in different stages; different opinions and expectations to reward and onerous task determines the responses to incentives; adjustment needs to be made as the change of the environment, for example, when low hierarchy of needs are met, higher levels of demand will appeared and the original need are likely to change.

When the managers planning to make research incentive mechanism of university's scientific research, if they want to raise the scientific research enthusiasm of teachers they should make it according to the different levels of demand for each stages teachers, not unification, to grasp the basic rule of demand change of young teachers, aiming at the different levels of young teachers the same needs to take corresponding countermeasures, is the most value leading level need if used properly, incentive effect is significant. University is a rendezvous for every field of elite talent; they have different psychological needs in different periods. Such as teachers with senior technical titles, in the their career is important to get to the next level of achievement, become the academic front and in the field of led, and achieved certain social status in the society, so they need more of is honorable incentives; but for the young teachers in colleges and universities, as a result of working time is shorter, the vast majority are more concerned about the school to give real incentive, in incentive theory, these aspects belong to the security requirements and survival needs. So if the college administrators master these factors, they can establish a reasonable mechanism aimed at meeting young teachers' demand. The incentives for young teachers should consider different levels of universality, respect the particularity and the characteristics; therefore, these mechanisms can promote the scientific research work in colleges and universities to a great extent. 


\section{Conclusion}

If the university scientific research management work wants to adhere the people-centered principle, we should treat the arousing of people's initiative, creativity, and participation as the ultimate goal. Humanistic management tells us that people is the core of the management, it in the leading position and is the key factor. The core concept of humanistic management mainly includes: respect idea, trust idea, rely idea, understand idea and care it. People's enthusiasm and innovative ability need constantly excavate and move. The material and spiritual needs in different stages should be satisfied in order to improve people's quality and ability in the round. Therefore, we should take care, love, and respect every teacher. The people-oriented is the key to design incentive mechanism. It should in accordance with the rules of the development of scientific research and accords with the laws of their own development needs. Therefore, the incentive mechanism will promote young teachers positively, reflect self-value, get respect, achievement and recognition.

In conclusion, the construction of scientific research incentive mechanism for young teachers in colleges and universities, will always adhere to the concept of development, give full consideration to the needs of the young teachers, meet the needs of young teachers' personality development, meet the needs of young teachers to realize their own value, meet the needs of young teachers development potential, inspire young university teachers' career pursuit, professional dedication and sense of responsibility, building a scientific research platform in the school for their rapid growth in order to make them become a mainstay of the education teaching front, become a powerhouse of scientific research in colleges and universities.

\section{References}

[1] He Baoguo. Analysis on the management incentive mechanism for colleges and universities teachers [J]. China Economist. 2010 (10).

[2] Gao ena, Wang Da-yong. Under the perspective of research universities to explore the incentive mechanism of young teachers [J]. Journal of Beijing Education (High Education). 2013 (Z1).

[3] Zhang Kuixing. The exploration and practice of training of young teachers of colleges and universities [J]. Journal of education BBS teaching. 2013 (24).

[4] Zhang Suluo Zhang Tao, Wen Jing, Gan Wenxiao. The needs of young university teachers cultivation mechanism research based on growth stages-investigation and thinking of Hebei Agricultural University [J]. Journal of Hebei Agricultural University (Agriculture and Forestry Education Edition), 2012 (05).

[5] Yang Xianxia. Thinking about how to establish the teacher incentive mechanism [J]. Education and Vocation. 2011 (12).

[6] Zhang Jianhua. Study on the comprehensive ability cultivation mechanism of young teachers in "The third level university" [J]. Continue Education Research. 2012 (05).

[7] Tao Jiayu, Cui Hongliang, Tu Xiaohua, Xu xiaoling. The existing problems and countermeasures in the incentive mechanism for college teachers [J]. Jiangxi Chemical Industry. 2010 (01). 